\title{
The Effect of Aluminizing Nb Refractory Metal Surface on Increasing Oxidation Resistance
}

\author{
Pinar Koymen Cagar (Corresponding author) \\ Dokuz Eylul University, The Graduate School of Natural and Applied Science, \\ Tinaztepe Campus, Buca, Izmir, PO box 35160, Turkey \\ E-mail: pinarkoymen@hotmail.com \\ Ali Bulent Onay \\ Dokuz Eylul University, The Graduate School of Natural and Applied Science, \\ Tinaztepe Campus, Buca, Izmir, PO box 35160, Turkey \\ E-mail:bulent.onay@deu.edu.tr bulentonay@gmail.com
}

\begin{abstract}
In order to increase oxidation resistance of $\mathrm{Nb}$ refractory metal, Aluminizing and Aluminizing + Siliconizing with co-deposition were applied to its surface through the method of Halide-activated pack cementation (HAPC). The characterization of diffusion coating was conducted via the analyses of SEM, XRD, and EDS. After that, oxidation tests were conducted, and the effect of coating on oxidation resistance was examined. As a result, according to XRD analysis, it was found that there were $\mathrm{Nb}_{5} \mathrm{Si}_{3}$ phase structures in both coatings. In addition to this, $\mathrm{Nb}_{5} \mathrm{Si}_{3}$ and $\mathrm{Nb}_{3} \mathrm{Si}$ phases emerged in co-deposition coating. Protective $\mathrm{NbSi}_{2}$ phase was not observed because an activator with fluoride was used but an activator with chloride was not. Both methods increased the oxidation resistance of $\mathrm{Nb}$. However, it was observed that the target value which was "metal loss of $25 \mu \mathrm{m}$ at $1300^{\circ} \mathrm{C} 100$ hours after oxidation" was not obtained only through cementation aluminizing process. We are indebted to TUBITAK for their support.
\end{abstract}

Keywords: Refractory metals, oxidation, pack cementation, co-deposition, aluminizing

DOI: $10.7176 / J S T R / 5-10-12$

\section{Introduction}

As of the 1970s, Ni-based metal alloys have started to replacing steel. As a result of mixing these alloys with various elements and heat treatment, new generation metallic engineering materials which are defined as "superalloys" have emerged. Through these alloys, the service temperatures of heat-energy conversion systems could be increased to $900^{\circ} \mathrm{C}$ (Stringer 1975). These systems can be exemplified by steam and gas turbines used to produce electricity, motors of aircraft and spacecraft, and rockets developed for defense industry.

Although superalloys are still used for the abovementioned purposes, productivity growth in energy conversion systems since 1980s has been possible with the development of the methods to cool the parts made of these superalloys and oxidation-resistant coating techniques (Perepezko 2009). As a result of these developments, the operating temperature of metallic materials has gone above $1000^{\circ} \mathrm{C}$. In order to sustain productivity growth, it is necessary to introduce both creep-resistant and oxidation-resistant materials at temperatures above $1200^{\circ} \mathrm{C}$, though.

Today, Nickel (Ni) and Cobalt (Co) based superalloys with high strength and oxidation resistance used in electric power generation systems, aircraft, and space vehicles approach the limits of use $\left(\sim 1200^{\circ} \mathrm{C}\right)$; therefore, there is a need for engineering materials with improved mechanical properties and oxidation resistance which can operate at higher temperatures than now. The new materials with these properties are refractory metals with melting temperatures higher than $2000^{\circ} \mathrm{C}$. The studies on refractory metals that started in the 1960s in the USA are still being conducted in lots of countries, yet there are no materials at the technically and commercially desired level. The studies based on Niobium $(\mathrm{Nb})$ have become prominent since this metal has the lowest density in this group (Briant 2000). 
However, the oxidation resistance of refractory metals is low even at $1000^{\circ} \mathrm{C}$. The main reason for this is that refractory metal oxides are not protective. To illustrate, because $\mathrm{Nb}$-oxides formed in air at 700 $1200^{\circ} \mathrm{C}$ have different crystal structures, and their volume is higher than the volume of oxidized metal (Pilling-Bedford ratio >2), oxide layers can easily fall off the metal (Dokumacı \& Önay 2008).

Habazaki has concluded that Mo refractory metal has low oxidation resistance; oxidation products evaporate or fall off at temperatures like $500^{\circ} \mathrm{C}$ (Habazaki et al., 1999). Perkins and Meier have produced alloys by adding some elements such as $\mathrm{Ti}, \mathrm{V}, \mathrm{Hf}, \mathrm{Zr}, \mathrm{Cr}, \mathrm{Mn}, \mathrm{Si}$, and $\mathrm{Be}$ to $\mathrm{Nb}$ in order to increase oxidation resistance, but they have observed that their melting temperatures are a lot lower than the melting temperature of $\mathrm{Nb}$. Therefore, they have asserted that such refractory metal-based alloys cannot be used in energy conversion and aviation systems at the temperatures over $1000^{\circ} \mathrm{C}$ for a long time without any coating (Perkins \& Meier 2008).

The studies on increasing the oxidation resistance of refractory metals conducted up to now can be divided into two groups. One of them is alloying these metals with other elements, and the other one is applying oxidation-resistant surface treatments to the surfaces of these metals.

"Cementation" method, which was applied in this study as well, is generally known as a surface modification method applied in order to harden the surfaces of low carbon steels. In addition to this, it is a "coating" process also called "chromizing" and "aluminizing" in order to increase the oxidation resistance of ferritic and austenitic steels at high temperatures (Üstel, 2006). "Cementation" method has been improved with the studies conducted by Rapp, et al., since the 1990s, and this method which is also known as "pack cementation" (Halide-Activated Pack Cementation; HAPC) has enabled coatings in complex compositions by coating more than one element simultaneously over the sample surface (codeposition) (Bianco, et al. 1991). Today, HAPC is frequently applied in order to prevent the oxidation of water and steam panels, boilers and pipes at energy plants producing electricity with pressurized steam and petrochemical plants at high temperatures (Rapp, 1993).

Majumdar, et al., studied the co-deposition of $\mathrm{Al}$ and $\mathrm{Si}$ with the refractory metals like $\mathrm{Ta}$ and $\mathrm{Nb}$ by the HAPC method. In the first study which lasted for 16 hours at $1027^{\circ} \mathrm{C}$, they observed that the elements $\mathrm{Ta}, \mathrm{Si}$, and $\mathrm{Al}$ were formed in the areas close to the surface of the Ta sample, and "thin layers" were formed in the $\mathrm{Nb}$ sample where the elements $\mathrm{Nb}, \mathrm{Si}$ and $\mathrm{Al}$ existed together. Below these layers, some areas where the silicide phases of both metals $\left(\mathrm{TaSi}_{2}\right.$ or $\left.\mathrm{NbSi}_{2}\right)$ were found to be approximately $40 \mu \mathrm{m}$ thick. It was indicated that there was no significant change in the weight of the samples in the oxidation experiments conducted in air for 10 hours at $1300^{\circ} \mathrm{C}$; therefore, they were resistant to oxidation, and the reason for which was thin oxide layers formed on the outermost surfaces. In a recent study on the stability of $\mathrm{Nb}$ compounds, the same authors stated that based on theoretical modeling, $\mathrm{Nb}$ metal would tend to form compounds with $\mathrm{Si}$ instead of Al (Majumdar et al. 2006, 2010). Ukegawa also specified that $\mathrm{NbSi}_{2}$ phase was formed during the diffusion of the element $\mathrm{Si}$ towards the $\mathrm{Nb}$ substrate. However, they concluded that complex phases like $\mathrm{Nb}_{5} \mathrm{Si}_{3}$ were formed at the interfaces between this phase and $\mathrm{Nb}$, which accelerated the oxidation of the $\mathrm{Nb}$ metal. Another result observed in the aforementioned study was that the element B decelerated Si diffusion (Ukegawa, et al. 2009). Knittel developed complex silicide compounds, and they were applied to the surfaces of pure $\mathrm{Nb}$ substrate and some $\mathrm{Nb}$ alloys by the HAPC method. Then they observed that their high-temperature oxidation resistance increased in the oxidation experiments carried out in air at $1100-1300^{\circ} \mathrm{C}$ (Knittel et al. 2013).

The purpose of this study is to increase the oxidation resistance of $\mathrm{Nb}$ refractory metal which has low oxidation resistance at temperatures higher than $800^{\circ} \mathrm{C}$ in environments like air, even though its melting temperature is higher than $2000^{\circ} \mathrm{C}$. For this purpose, two different test systems were applied. Aluminizing with pack cementation method and aluminizing + siliconizing surface modifications with the HAPC codeposition method were applied on the $\mathrm{Nb}$ substrate. Then they were compared in terms of their resistance to high temperature oxidation.

In this context; first, pure $\mathrm{Nb}$ was oxidized, and its oxidation behavior was examined. After that, aluminizing was performed by pack cementation in order to increase the oxidation resistance of $\mathrm{Nb}$, and $\mathrm{Nb}$ aluminate diffusion layer was formed on the surface. Then aluminizing+siliconizing process was performed by the HAPC co-deposition method in order to increase the oxidation resistance of another pure $\mathrm{Nb}$ substrate group. Oxidation tests were performed; weight changes were examined, and oxidation behaviors were interpreted. 


\section{Methodology}

In this study, $\mathrm{Nb}$ refractory metal bars which were $99.9 \%$ pure were used as substrates. The substrates were embedded in a powder mixture in a stainless steel protective tube after the procedures of cutting, polishing, cleaning, and weighing. This stainless steel tube protects the substrates against the oxygen in the furnace.

Two different HAPC test systems were used. In the first test system, the $\mathrm{Nb}$ substrate was aluminized in the furnace by pack cementation method. The powder mixture used in this test system includes Aluminum (Al) as the element to be released, Sodium Fluoride (NaF) as activating salt that takes Aluminum to the vapor phase and Alumina $\left(\mathrm{Al}_{2} \mathrm{O}_{3}\right)$ as filler to prevent sintering of powders at test temperatures (Table 1). In the second one, the $\mathrm{Nb}$ substrates were aluminized + siliconized by co-deposition method which enabled the development of coatings with complex composition. In the second test system, the powder mixture in which the $\mathrm{Nb}$ substrate was embedded includes Aluminum (Al) and Silicon (Si) as the elements to be released, $\mathrm{NaF}$ as activating salt that takes Aluminum to the vapor phase and Al203 as filler to prevent sintering of powders at test temperatures (Table 2). Carburizing powders are 325 mesh particles in size. In both test systems, the $\mathrm{Nb}$ samples were exposed to cementation at $950^{\circ} \mathrm{C}$ for 6 hours in a pack furnace, and aluminizing and co-deposition were carried out.

Table 1. Two different procedures

\begin{tabular}{|c|c|c|c|c|c|c|c|c|}
\hline $\begin{array}{c}\text { Sample } \\
\text { Group }\end{array}$ & Base & $\begin{array}{c}\text { Aluminizing } \\
\text { with Pack } \\
\text { Cementation }\end{array}$ & $\begin{array}{c}\text { Aluminizing + } \\
\text { Siliconizing with } \\
\text { Co-deposition }\end{array}$ & SEM + EDS & XRD & Oxidation & XRD & ( \\
\hline I & $\mathrm{Nb}$ & $\mathrm{x}$ & $\mathrm{x}$ & $\mathrm{x}$ & $\mathrm{x}$ & $\mathrm{x}$ & $\mathrm{x}$ & \\
\hline $\mathrm{II}$ & $\mathrm{Nb}$ & & $\mathrm{x}$ & $\mathrm{x}$ & $\mathrm{x}$ & $\mathrm{x}$ & \\
\hline
\end{tabular}

Both sample groups were exposed to oxidation in the pack furnace. Oxidation resistance of the samples was compared by using oxide crusts and weight changes on the surface.

Table 2. Powder Mixtures for Pack Cementation

\begin{tabular}{|l|c|c|c|c|}
\hline Powder mixture (weight \%) & $\mathrm{Al}$ & $\mathrm{Al}_{2} \mathrm{O}_{3}$ & $\mathrm{NaF}$ & $\mathrm{Si}$ \\
\hline Mixture 1: Used in aluminizing & 15 & 80 & 5 & - \\
\hline Mixture 2: Used in co-deposition & 7 & 79 & 7 & 7 \\
\hline
\end{tabular}

In order to interpret the results after these experiments, Scanning Electron Microscope (SEM) was used for the analyses of coating thickness and surface grain structure; Energy Dispersive Spectroscopy (EDS) was used for the elemental analysis of substrates and coatings; X-Ray Diffractometer (XRD) was used for phase analysis, and Thermogravimetric Analysis (TGA) was performed for long term oxidation tests.

\section{Results and Discussion}

\subsection{Results of Cementation}

Figure 1 shows a cross-sectional SEM/BE image of pure $\mathrm{Nb}$ substrate which was aluminized at $950^{\circ} \mathrm{C}$ for 6 hours in a powder mixture including 15\% Al. The areas with lighter atoms in the sample look dark in the BE image. Accordingly, an Aluminum-rich coating with a thickness of about $70 \mu \mathrm{m}$ was realized on the surface of the substrate.

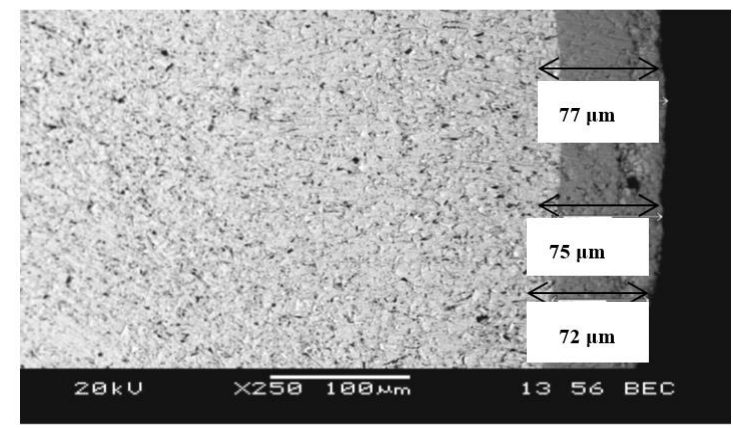

Figure 1. SEM cross-section analysis of $\mathrm{Nb}$ aluminized in a powder mixture including $15 \% \mathrm{Al}$

Table 3. EDS analysis of $\mathrm{Nb}$ from Zone 1 aluminized in a mixture including $15 \% \mathrm{Al}$ 


\begin{tabular}{|l|l|}
\hline Element & Weight \% \\
\hline $\mathrm{Al}$ & 36,516 \\
\hline $\mathrm{Nb}$ & 63,457 \\
\hline
\end{tabular}

Table 3 and Figure 2 show the EDS and XRD analysis results of this coating respectively. $\mathrm{NbAl}_{3}$ phase was observed in the XRD characterization of the coating. As seen in Majumdar's studies, this phase is one of the phases increasing the oxidation resistance of $\mathrm{Nb}$ (Majumdar et al. 2006, 2010).

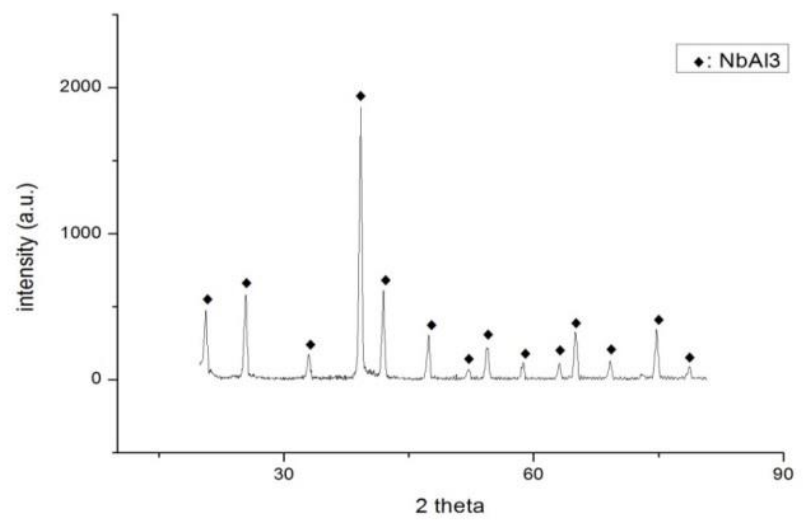

Figure 2. XRD thin film analysis of the $\mathrm{Nb}$ sample aluminized in a powder mixture including $15 \% \mathrm{Al}$

SEM and EDS analysis results of the co-deposition of $\mathrm{Al}$ and $\mathrm{Si}$ on $\mathrm{Nb}$ metal at $950^{\circ} \mathrm{C}$ for 6 hours are given in Figure 3 and Table 4 respectively. In the analysis, it can be seen that an Aluminum-rich coating is formed on the surface, but the amount of Al decreases toward the interior of the sample. The lightcolored structures seen in the diffusion coating zone in the SEM photo are the Nb-rich zones formed by the $\mathrm{Nb}$ atoms spreading towards the coating. In addition, according to EDS analysis (see Table 4), the $\mathrm{Nb}$ sample contains a small amount of $\mathrm{Si}$ in these zones. This is because the activator used in this study includes fluoride, and $\mathrm{Al}$ diffuses over the surface of $\mathrm{Nb}$ more than $\mathrm{Si}$ in an environment with fluoride. This finding is consistent with previous findings in literature. As it is mentioned in Rapp's study, the volatile halides of $\mathrm{Al}$ and $\mathrm{Si}$ differ significantly due to their thermodynamic stabilities. Therefore, the vapor pressure of volatile halide will be enough to carry only one element in case there is only one activator and more than one element to carry in the container where cementation procedure is realized. In the same thermodynamic activity, the element $\mathrm{Al}$ can be carried best in an environment with volatile fluorides, whereas the element $\mathrm{Si}$ can diffuse the best in an environment with volatile chlorides (Rapp, 1993).
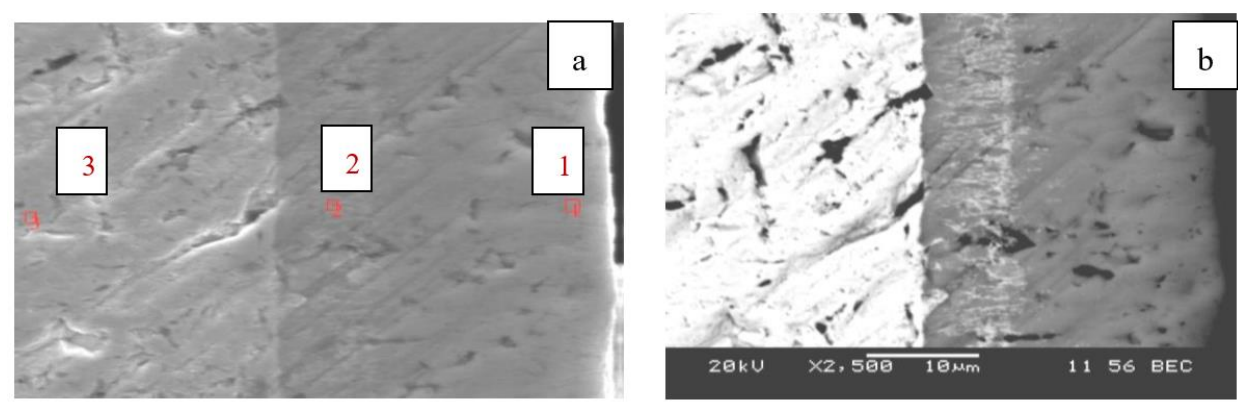

Figure 3. a) SEM / SE cross-sectional photo, b) SEM / BE cross-sectional photo of the codeposited Nb sample

Table 4. EDS analysis of the spots mentioned in Figure 3.a 


\begin{tabular}{|c|c|c|c|}
\hline Element & 1. (\% weight $)$ & 2. (\% weight $)$ & 3. (\% weight $)$ \\
\hline $\mathrm{Nb}$ & 63,3 & 75,66 & 99,99 \\
\hline $\mathrm{Al}$ & 36,4 & 19,3 & - \\
\hline $\mathrm{Si}$ & 0,2 & 5 & - \\
\hline
\end{tabular}

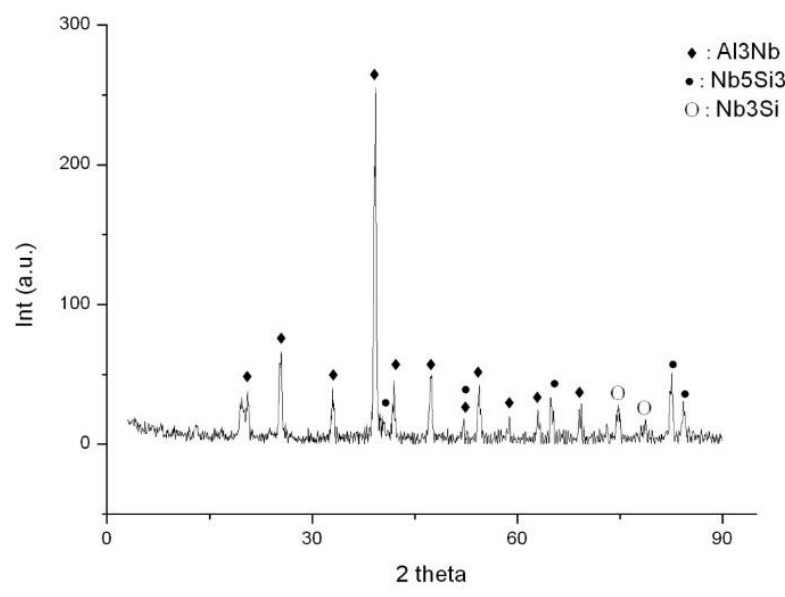

Figure 4. XRD thin film analysis of the co-deposited $\mathrm{Nb}$ sample

The XRD results in Figure 4 show the phases both $\mathrm{Al}$ and $\mathrm{Si}$ form with $\mathrm{Nb}$. Protective $\mathrm{NbAl}_{3}$ phase is seen here, as well. Also, $\mathrm{Nb}_{5} \mathrm{Si}_{3}$ and $\mathrm{Nb}_{3} \mathrm{Si}$ phases are seen. However, protective $\mathrm{NbSi}_{2}$ is not seen because the activator used was with fluoride, not with chloride.

\subsection{Results of Oxidation}

When pure $\mathrm{Nb}$ was oxidized at $800^{\circ} \mathrm{C}$ for 30 minutes, it was seen that a lot of oxide crusts flaked away from the surface, and $\mathrm{Nb}$ surface was completely covered with white oxide. This result is consistent with the result stated by Habazaki that oxidation products formed by refractory metals are not protective; they evaporate or fall off (Habazaki et al., 1999).

In order to determine the oxidation resistance of $\mathrm{Nb}$ samples which underwent surface treatments like cementation and co-deposition, the samples were placed in ceramic pots and exposed to cyclic oxidation test at the temperatures between $800-1200^{\circ} \mathrm{C}$ in the atmospheric environment in the pack furnace. After the sample was stored at $800^{\circ} \mathrm{C}$ for 1 hour, it was removed from the furnace for weighing. While the sample and, if any, the powder poured from the sample to the pot, were being weighed, the furnace temperature was increased by $100^{\circ} \mathrm{C}$. Then the sample was placed back in the furnace and stored at the aforementioned constant temperature for 1 hour. This procedure continued from $800^{\circ} \mathrm{C}$ to $1200^{\circ} \mathrm{C}$.

Table 5. Weight changes in the pack furnace as a result of cyclic oxidation

\begin{tabular}{|c|c|c|c|c|c|c|}
\hline & Surface treatment & $800 \circ \mathrm{C}$ & $900 \circ \mathrm{C}$ & $1000 \circ \mathrm{C}$ & $1100 \circ \mathrm{C}$ & $1200 \circ \mathrm{C}$ \\
\hline \multirow{3}{*}{ 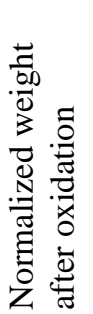 } & Pure $\mathrm{Nb}$ & $-0,0222$ & $-0,042$ & $-0,0449$ & $-0,0378$ & $-0,0521$ \\
\hline & Aluminized Nb & 0,0001 & 0,0002 & 0,0004 & 0,0001 & 0,0003 \\
\hline & $\begin{array}{l}\text { Analysis results of co- } \\
\text { deposited } \mathrm{Nb}\end{array}$ & 0,0001 & 0,0003 & 0,0007 & 0,0004 & 0,0029 \\
\hline
\end{tabular}

Table 5 shows the weight changes of the samples after oxidation. The weight of crusts flaked away during oxidation was not taken into account in the calculation of weight changes. Since oxide crusts flaked away 
from the surface of pure $\mathrm{Nb}$, the weight changes were negative. The oxide crusts of aluminized $\mathrm{Nb}$ did not flake away in cyclic oxidation tests, and their weight remained approximately constant. When the data in Table 5 are compared, its approximately constant weight indicates that the oxidation resistance of aluminized $\mathrm{Nb}$ is much higher than the co-deposited $\mathrm{Nb}$. Therefore, only the results of the studies on aluminized $\mathrm{Nb}$ are given below. XRD results in Figure 5 show the phases of aluminized and oxidized $\mathrm{Nb}$. In addition to the protective $\mathrm{NbAl} 3$ phase, various oxide phases are also observed.

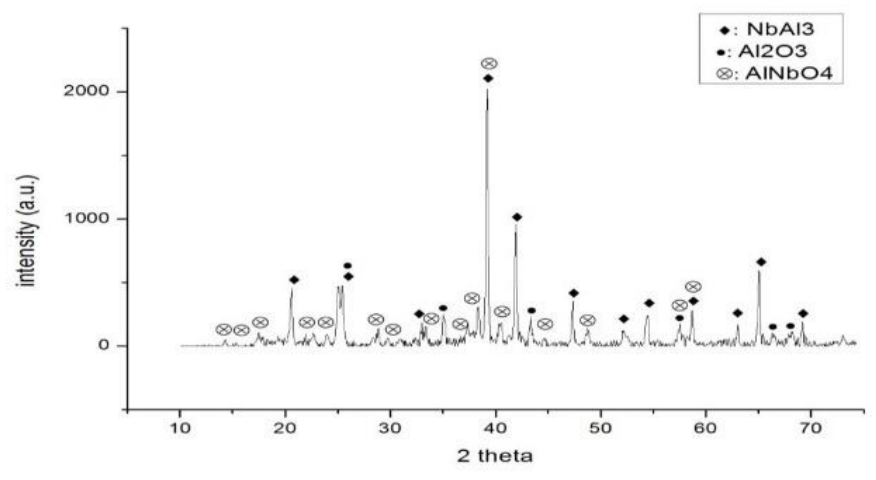

Figure 5. XRD analysis of the $\mathrm{Nb}$ sample oxidized at $1000^{\circ} \mathrm{C}$ after being aluminized

Since the test results of aluminized $\mathrm{Nb}$ sample showed that it gained resistance to oxidation at 800 $1200^{\circ} \mathrm{C}$, the oxidation tests of this sample were extended to $1300^{\circ} \mathrm{C}$. Two aluminized $\mathrm{Nb}$ samples were oxidized in air in the TGA instrument in order to observe their behaviors at higher temperatures. The first sample was placed in the TGA instrument at room temperature. Then the temperature was raised to $1300^{\circ} \mathrm{C}$ in $10^{\circ} \mathrm{C} / \mathrm{min}$ increments, and the sample was stored at $1300^{\circ} \mathrm{C}$ for 4 hours. During TGA analysis, it was observed that the sample weight increased linearly over time. The interior structure of the sample after TGA analysis is shown in Figure 6, and the chemical analyses of the spots marked are given in Table 6 . Figure 6 shows the formation of a $20-30 \mu \mathrm{m}$ thick oxide layer on the $50-60 \mu \mathrm{m}$ thick cementation layer formed during the experiment. Considering that the $20-30 \mu \mathrm{m}$ thick oxide layer formed in 4 hours during the experiment, it was observed that the purpose of the study, which was metal loss of $25 \mu \mathrm{m}$ at $1300^{\circ} \mathrm{C}$ 100 hours after oxidation, could not be obtained only through cementation aluminizing process. As for EDS analysis, it shows that the amount of $\mathrm{Al}$ and $\mathrm{O}$ decreases from surface to depth.
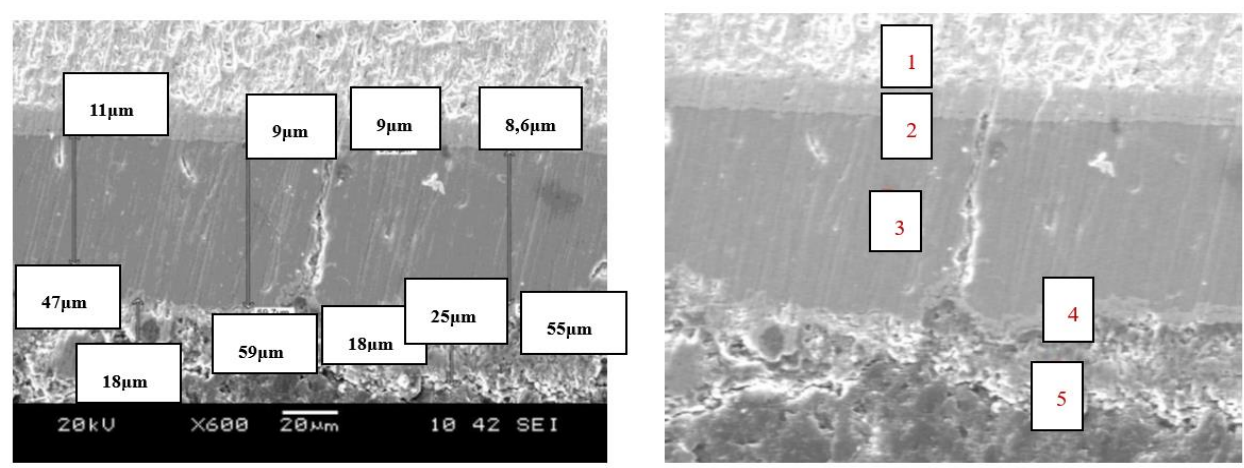

Figure 6. a) SEM photo b) EDS analysis of aluminized $\mathrm{Nb}$ after being oxidized at $1300^{\circ} \mathrm{C}$ for 4 hours

Table 6. EDS analysis of the spots mentioned in Figure.6b

\begin{tabular}{|c|c|c|c|c|c|}
\hline Element & 1 & 2 & 3 & 4 & 5 \\
\hline $\mathrm{Al}$ & 0.02 & 6.32 & 32.52 & 7.32 & 15.25 \\
\hline $\mathrm{O}$ & 0 & 0.03 & 0.064 & 0 & 2.58 \\
\hline $\mathrm{Nb}$ & 99.98 & 93.65 & 67.4 & 92.67 & 82.157 \\
\hline
\end{tabular}

The second aluminized sample was also placed in the TGA instrument at room temperature. The temperature was raised to $1000^{\circ} \mathrm{C}$ in $10^{\circ} \mathrm{C} / \mathrm{min}$ increments, and the sample was stored at this temperature 
for 75 hours. The SEM photo in Figure 7 shows a cementation layer of 71-77 $\mu \mathrm{m}$ thickness on the sample surface and an unspecified oxide layer which is thought to be less thick than $10 \mu \mathrm{m}$. It can be said that the weight increase progressed more slowly than the experiment at $1300^{\circ} \mathrm{C}$ and even showed parabolic behavior. As a result of EDS analysis which can be seen in Table 7, oxygen was detected on the sample surface. This suggests that it could be possible to obtain metal loss of $100 \mu \mathrm{m}$ at $1100^{\circ} \mathrm{C}$ after 100 hours, which was targeted as plan B of the study.
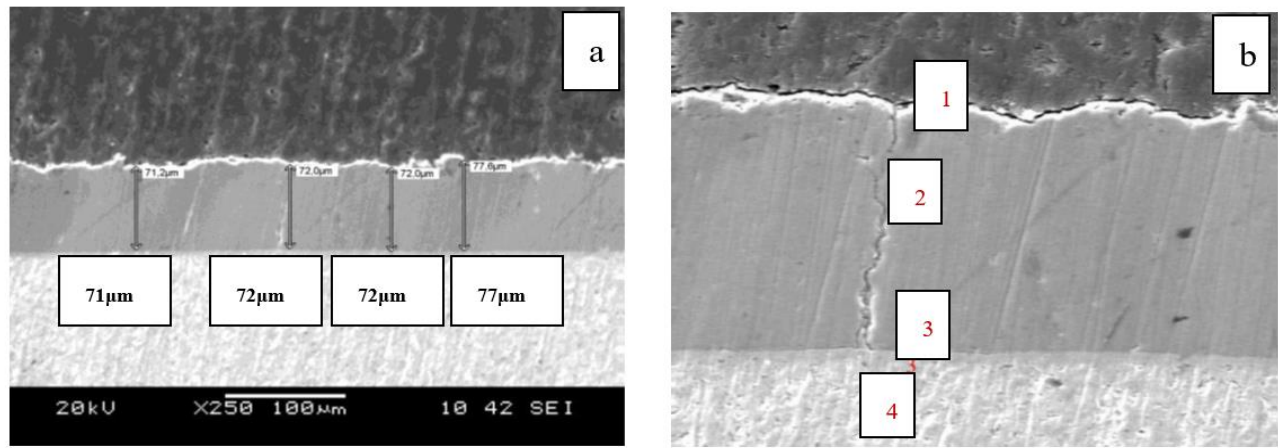

Figure 7. a) SEM photo b) EDS analysis of aluminized $\mathrm{Nb}$ after being oxidized at $1000^{\circ} \mathrm{C}$ for 75 hours

Table 7. EDS analysis of the spots mentioned in Figure.7b

\begin{tabular}{|c|c|c|c|c|}
\hline Element & 1 & 2 & 3 & 4 \\
\hline $\mathrm{Al}$ & 33.23 & 32.53 & 3.51 & 0 \\
\hline $\mathrm{O}$ & 2.21 & 0 & 0 & 0.14 \\
\hline $\mathrm{Nb}$ & 64.54 & 67.46 & 96.48 & 99.86 \\
\hline
\end{tabular}

\section{Conclusion}

This study indicates that it could be possible to increase the oxidation resistance of pure $\mathrm{Nb}$ refractory metal at high temperatures through methods of cementation. Cementation was applied to the surface of $\mathrm{Nb}$ refractory metal in two ways: aluminizing and aluminizing+siliconizing with co-deposition. According to XRD analysis, only the coatings including the element $\mathrm{Al}$ were in $\mathrm{NbAl}_{3}$ phase structure. It was observed that $\mathrm{NbAl}_{3}$ phase was formed besides $\mathrm{Nb}_{5} \mathrm{Si}_{3}$ and $\mathrm{Nb}_{3} \mathrm{Si}$ phases in co-deposition coatings. It was also observed that in the same thermodynamic activity, the diffusion of the best Al over the surface of $\mathrm{Nb}$ was more than $\mathrm{Si}$ in the presence of volatile fluorides because the activator used was with fluoride. This explains the absence of $\mathrm{NbSi}_{2}$ phase in XRD analyses. The phases observed as a result of XRD analyses were in protective structure, which is consistent with previous findings of our experimental studies and in literature.

According to the short and long term isothermal and cyclic oxidation test results, it was observed that it could be possible to increase the oxidation resistance of $\mathrm{Nb}$ samples through cementation. $20-30 \mu \mathrm{m}$ thick oxide layer formed during TGA analysis was formed at $1300^{\circ} \mathrm{C}$ in 4 hours, and oxide crust began to flake away. According to this, the target value which was metal loss of $25 \mu \mathrm{m}$ at $1300^{\circ} \mathrm{C} 100$ hours after oxidation could not be obtained only through cementation aluminizing. The oxide crust of the sample exposed to oxidation at $1000^{\circ} \mathrm{C}$ for 75 hours did not flake away. This indicates that the oxide crust on the surface increased rapidly above $1000^{\circ} \mathrm{C}$, and this suggests that it may be possible to obtain metal loss of $100 \mu \mathrm{m}$ at $1100^{\circ} \mathrm{C}$ after 100 hours.

\section{Acknowledgment}

We would like to thank TUBITAK for their financial support of this article based on a 1001 project numbered 111M652.

\section{References}

Briant, C.L. (2000). New Applications for Refractory Metals, JOM, Mach 2000, 36

Dokumac1, E. \& Önay, B. (2008). Oxidation Behavior of Mo Containing Alloys”, Materials Science Forum, Editör: Wohlbier,T., Trans Tech Publications.

Habazaki, H., Hon-Yashiki, K., Ito, K., Mitsui, H., Kawasashima, A., Asami, K. et al., (1999). 
Sulfidation and oxidation-resistant alloys prepared by sputter deposition. Materials Science and Engineering, A267, 267-276.

Knittel, S., Mathieu, S., Portebois, L., Drawin,S.\& Vilasi, M. (2013). Development of Silicide Coatings to Ensure the Protection of $\mathrm{Nb}$ and Silicide Composites Against High Temperature Oxidation. Surface and Coatings Technology, 235, 401-406.

Majumdar, S. (2006). Development of Multilayer Oxidation Resistance Coatings on Niobium and Tantalum. Surface and Coatings Technology, 200, 3713-3718.

Majumdar, S. (2010). Deposition of Aluminide and Silicide Based Protective Coatings on Niobium. Applied Surface Science, 257, 635-640.

Perepezko, J. H. (2009). The Hotter the Engine, the Better. Science, 326, 5956, 465-550.

Perkins, R. A. \& Meier, G. H. (2008). The Oxidation Behavior and Protection of Niobium. JOM, August 1990, 17-21.

Rapp (1993), The Codeposition of Elements in Diffusion Coatings by the Pack Cementation Method. Materials at High Temperatures, Volume 11 pp.1-4

Stringer, J. (1975). High Temperature Corrosion of Aerospace Alloys. AGARD-AG-200 Report, USA. 